\title{
THE IMPLICATIONS OF NUTRITION SERVICES WITHIN THE HEALTH CARE SYSTEM ON THE QUALITY OF LIFE AND LONGEVITY, IN DEVELOPED COUNTRIES: A RE-ANALYSIS OF 38 STUDIES
}

\author{
Stefanos Tyrovolas ${ }^{1}$, Yannis Tountas ${ }^{2}$, Evangelos Polychronopoulos ${ }^{1}$, Demosthenes B. Panagiotakos ${ }^{1}$ \\ 'Department of Nutrition - Dietetics, Harokopio University, Athens, Greece \\ ${ }^{2}$ Department of Hygiene, Epidemiology and Medical Statistics, School of Medicine, University of Athens, Athens, Greece
}

\begin{abstract}
SUMMARY
Background: The United Nations' Global Population Pyramid is undertaking a shift from pyramid to cube. The concomitant decline in fertility and mortality rates produces a higher portion of older people, and, thus, an increased number of deaths due to cancer and cardiovascular disease (CVD). Limited studies have investigated the effect of health care services on longevity. In this work, findings from studies throughout the world are presented and re-analysed in order to evaluate the effect of health care services on population's health status.

Methods: Studies that have assessed the associations of nutritional and other health care services (i.e., physicians supply, technical support, intercollaboration) on longevity and health status were retrieved (searches in PubMed, EMBASE, Scopus, up to January 2010), and summarized here.

Results: Few studies, mostly located in the US and the UK, have evaluated the role of health care services on population's health status. The majority of the studies reported a beneficial association between the frequency of physicians and mortality, while some other studies reported weak or no associations between physician's supply and longevity. Also nutritional services (screening) seem to promote better clinical outcome.

Conclusion: Although very few data are available, it seems that there is a positive correlation between the quality and quantity of health care services and longevity. Strong primary health care seems to be effective on the population's health outcome. Active health policy and enhancement of health and nutritional services within the health care system may contribute to improved population's health and their overall quality of life.
\end{abstract}

Key words: health care systems; health care services; nutritional services; physicians; mortality; longevity

Address for correspondence: D. B. Panagiotakos, 46 Paleon Polemiston St., 16674 Glyfada, Attica, Greece. E-mail: d.b.panagiotakos@usa.net

\section{INTRODUCTION}

Health care is produced by system inputs (i.e., physicians, medicines, facilities) that interact within the population through various processes, like medical consultations, surgeries, deliveries, and result in health outcomes (1). Public Health, as an organized effort of society, espouses several principles, namely: a) emphasis on collective responsibility and role of the state; b) focus on whole populations; c) emphasis on prevention; d) concern for the underlying socio-economic determinants of health and disease; e) multi-disciplinary approach (both quantitatively and qualitatively); and f) partnerships with populations served (2, 3). It is known that health care services are categorized in three different groups: primary, secondary and tertiary care providing a variety of effective basic and completed services $(4,5)$. Furthermore, nutritional care compromise a basic part of heath care services. The nutritional support contains four distinct steps: a) nutrition assessment, b) nutrition diagnosis, c) nutrition intervention and d) nutrition monitoring and evaluation (6). Through nutritional care, dieticians and nutrition practitioners could promote therapeutic lifestyle changes and better quality of life at individual and community level through counselling and education (7).
Public health focuses on population's health. There are many determinants which are commonly classified as either proximal or distal (8). These health determinants have deep effect on life expectancy. The health care system, which operates at proximal level, shares an interface with other sectors of organized societies such as the social, political and economic systems. Health care system inputs such as physicians and medical technology may be the result of inter-sectoral dynamics and social choices. It is expected that public health care systems can influence many of the proximal non-medical determinants and avert or minimize the need for expensive medical care. This is also why the new public health plan hopes to address major risk factors implicated in the global burden of disease (9).

Developed populations currently enjoy unprecedented wealth and longevity (10). According to the World Health Organization (WHO), the proportion of people over the age of 60 is growing faster than any other age groups (11). With the increasing emphasis on health and the progressive lengthening of the average life span, both scientific community and general public have been examining ways to improve well-being and to prevent disease at every stage of life. Globally, CVD and cancer are the leading causes of mortality and loss of disability-adjusted life years (12). 
It is expected that health care systems can influence many of the modifiable risk factors and increase quality of life, while avert or minimize the need for expensive medical care. Medical services, composed of preventive services and therapeutic interventions, seem to add almost five years increase in life expectancy since 1900, and almost seven years of increase since 1950 (13).

There has been a longstanding debate within researchers as to whether longer life is associated with a compression, an expansion of morbidity, or a combination of both, with an increased prevalence of chronic diseases counterbalanced by a decrease in the severity and consequences of the same diseases (14). Nonetheless, there are accumulating data that the prevalence of chronic disability is decreasing in longer-living persons. Furthermore, longer life is also accompanied with a better quality of life (15, 16). The role of a healthy lifestyle and behaviour, such as a healthy diet that includes moderate alcohol, low fat, and rich in fruit and vegetable consumption, daily exercise, avoidance of smoking, and low depression and stress levels, in the prevention and control of morbidity and premature mortality due to non-communicable diseases, has been well-established by the vast population-based epidemiological research carried out over the last three decades (17-21). However, what ageing people aspire for, is not only longer life but also optimal quality of life - free of disability or disease - that implies being dependent on others. As a higher self-rating of health is associated with reduced mortality- not only among elderly people but among the general population as well-identifying which factors contribute to manage healthy aging is the key of the percentage increase of the population who enjoys their longevity (22).

All services that can be offered by the health care system are considered as health care services. However, health care services are a scientific issue comprised of many different components (such as the supply of physicians and health outcomes, the people's relationships with a primary or special care practitioner, services costs and health care, health services care, disparities and health outcomes, etc.). This work focuses on the studies that investigated the association of health care services with chronic diseases outcomes, in middle aged and older populations, and especially the role of general and specialised physicians, as well as the role of nutritionists and nutritional care.

\section{METHODOLOGY}

\section{Selection of studies}

Original-research studies that were published in English, between 1975 and January 2010, were selected through a computerassisted literature search (i.e., PubMed http://igm.nlm.nih.gov, EMBASE and Scopus www.scopus.com). The electronic search focused on two basic steps. Firstly, the computer searches used combinations of keywords related to population's health (i.e., cardiovascular and cancer diseases, all cause mortality, longevity, overall health outcome, overall population health) and health care services (i.e., primary care physicians supply, family and special care physician's supply). Secondly, the searches focused on keywords related to the clinical and health outcome (i.e., cardiovascular risk, clinical outcome, overall health outcome) and nutritional services (i.e., nutrition services, nutrition support, nutrition screening, dietary advices, etc). In addition, the reference lists of the retrieved articles assisted us in finding relevance to the present articles that were not allocated through the searching procedure.

\section{Retrieved information}

A fixed protocol for the information extracted by each paper was followed: design of study (cross-sectional, longitudinal cohort or review, interventions), studies from well-off countries, sample size, age (adult population) and sex of participants, essay methods, and degree of adjustment for potential co-founders (i.e., geographical regulation, health care system covariates, income). However, studies involving pregnant women or any studies on patients younger than 18 years were excluded. Studies that examining artificial nutritional support (e.g. oral nutritional supplements, enteric or parenteric nutrition), were also excluded.

Thus, 32 observational studies were selected and discussed here; 10 of them were longitudinal, 21 cross-sectional and 1 was a review study with presentation of secondary data (Table 1). Furthermore, six intervention studies have also been allocated and summarised here (Table 2).

\section{RESULTS}

Seventeen out of $32(53 \%)$ studies, reported that the health care system plays a significant role in population's health, 7 out of $32(22 \%)$ reported a moderate or weak association, 6 out of 32 $(19 \%)$ reported no association and 2 out of 32 reported inverse association (6\%) (Fig. 1).

Furthermore, 24 of the studies refer that the health care system plays a positive role in life-expectancy of population. Of them $12(50 \%)$ reported that a strong primary care plays a significant role in life expectancy of population, 3 out of 24 (12.5\%) reported a moderate or weak association between the number of special physicians and mortality of population, 6 out of $24(25 \%)$ reported that the total number of physicians (general and specialists) and medical care have a significant beneficial role in longevity and 3 out of $24(12.5 \%)$ reported no association between physicians and population's life expectancy (Fig. 2). None of these studies evaluated the influence of other components of health care system which may play a role in population health, such as dieting component.

Finally, summarizing the findings from interventional studies with nutritional support, 5 out of $6(83 \%)$ reported that nutritional screening plays a significant role in clinical outcome and 1 out of $6(17 \%)$ mentioned a moderate or weak association (Fig. 3). It is of interest that almost none of these studies evaluated the influence of any aspect of nutritional support in population's health.

\section{DISCUSSION}

\section{Health care services and population's health}

There has been a series of research reports that have described associations between the supply of primary care physicians and health outcomes, such as cardiovascular and cancer mortality 
Table 1. A summary of population studies that evaluated the role of Health Services on population's health

\begin{tabular}{|c|c|c|c|}
\hline Studies & Design & Sample & Main finding(s) \\
\hline Shi et al. (31-34) & Cross-sectional & Adult U.S. population & $\begin{array}{l}\text { Enhancing primary care, particularly family medicine, even in states } \\
\text { with high levels of income inequality, led to lower all-cause mortality. }\end{array}$ \\
\hline Starfield et al. $(29,30)$ & Cross-sectional & Adult U.S. population & $\begin{array}{l}\text { Populations do not necessarily benefit from an overabundance of } \\
\text { specialists in a geographic area. The increasing of supply in primary } \\
\text { care physicians would have a beneficial impact on the health of the } \\
\text { population. }\end{array}$ \\
\hline Masinco et al. (8) & $\begin{array}{l}\text { Pooled, cross-sectional, } \\
\text { time series analysis }\end{array}$ & $\begin{array}{l}\text { Adult population from } 18 \\
\text { OCED countries }\end{array}$ & $\begin{array}{l}\text { Strong primary care system and practice characteristics were associ- } \\
\text { ated with improved health. }\end{array}$ \\
\hline Young (28) & Cross-sectional & $\begin{array}{l}\text { Adult population from the } \\
\text { Japanese, USA prefec- } \\
\text { tures, and European } \\
\text { countries }\end{array}$ & $\begin{array}{l}\text { The availability of medical specialists had little impact on mortality } \\
\text { rates in competition with the social and economic variables that were } \\
\text { used as controls. }\end{array}$ \\
\hline Or (35), Or et al. (36) & $\begin{array}{l}\text { Pooled, cross-sectional, } \\
\text { time series analysis }\end{array}$ & $\begin{array}{l}\text { Adult population from } 21 \\
\text { OCED countries }\end{array}$ & $\begin{array}{l}\text { No. of physician is an important determinant of mortality; cross-coun- } \\
\text { try heterogeneity in the effect of physician availability on health. }\end{array}$ \\
\hline Gulliford et al. $(45,46)$ & Cross-sectional & Adult English population & $\begin{array}{l}\text { Mortality was weakly associated with the degree of organisation of } \\
\text { practices as represented by the partnership size, but not with the } \\
\text { supply of GPs. }\end{array}$ \\
\hline Aakvik and Holmas (44) & Longitudinal study & $\begin{array}{l}\text { Adult Norwegian popula- } \\
\text { tion }\end{array}$ & $\begin{array}{l}\text { No relationship between mortality and No. of GPs per capita was } \\
\text { found. There is a significant effect of the composition of GPs. }\end{array}$ \\
\hline Robst and Graham (37) & Cross-sectional & Adult U.S. population & $\begin{array}{l}\text { No. of physicians in a county has a positive influence on the health } \\
\text { status of individuals in rural areas. Older people benefit more from } \\
\text { the presence of physicians than younger people. }\end{array}$ \\
\hline $\begin{array}{l}\text { Mackenbach et al. }(25 \text {, } \\
26,40)\end{array}$ & Longitudinal study & Dutch population & $\begin{array}{l}\text { Inverse associations between mortality and presence of university } \\
\text { hospitals, but also found an unexpected positive associations with } \\
\text { general practitioner density. }\end{array}$ \\
\hline $\begin{array}{l}\text { McKeown (23), McKeown } \\
\text { and Brown (38), McKeown } \\
\text { and Record (39) }\end{array}$ & Longitudinal study & Adult English population & $\begin{array}{l}\text { The rise of population was due primarily to the decline of mortality } \\
\text { and the most important reason for the decline was an improvement in } \\
\text { economic and social conditions. }\end{array}$ \\
\hline Cochrane et al. (41) & Cross-sectional & $\begin{array}{l}\text { Population from } 18 \text { devel- } \\
\text { oped countries }\end{array}$ & $\begin{array}{l}\text { The indices of health care are not associated with mortality. There is } \\
\text { a positive association between the No. of physicians and mortality in } \\
\text { the younger age groups. }\end{array}$ \\
\hline $\begin{array}{l}\text { McKinlay and McKinlay } \\
\text { (24) }\end{array}$ & $\begin{array}{l}\text { Review study with presen- } \\
\text { tation of secondary data }\end{array}$ & U.S. population & $\begin{array}{l}\text { Medical care could account for very little of the overall decline in } \\
\text { mortality }\end{array}$ \\
\hline Bunker et al. (27) & Longitudinal study & $\begin{array}{l}\text { U.S. and English popula- } \\
\text { tion }\end{array}$ & $\begin{array}{l}\text { Medical care can be credited with three of the roughly seven years of } \\
\text { increased. } \\
\text { Clinical services with the potential of extending life expectancy by } \\
\text { an additional one and a half to two years if they were provided more } \\
\text { widely. }\end{array}$ \\
\hline $\begin{array}{l}\text { Poikolainen and Eskola } \\
\text { (43) }\end{array}$ & Cross-sectional & Adult Finish population & $\begin{array}{l}\text { Mortality from amenable causes was inversely associated with gross } \\
\text { domestic product, but not with the No. of physicians, nurses, hospital } \\
\text { beds etc. }\end{array}$ \\
\hline Mansfield et al. (47) & Cross-sectional & U.S. population & $\begin{array}{l}\text { Borderline relationship between premature mortality and supply of } \\
\text { primary care physicians }\end{array}$ \\
\hline Alter et al. (48) & Cross-sectional & Adult Canadian population & $\begin{array}{l}\text { The mismatch between physician supply and CVD burden may } \\
\text { explain why health service is neither concordant with the CVD burden } \\
\text { nor associated with mortality. }\end{array}$ \\
\hline Lee et al. (49) & Cross-sectional & Adult Korean population & $\begin{array}{l}\text { No. of primary care physicians was positively associated with lower } \\
\text { all-cause mortality, cancer mortality, and CVD mortality. The ratio of } \\
\text { primary care physicians-to-specialists was not related to all-cause } \\
\text { mortality. }\end{array}$ \\
\hline Campbell et al. (50) & Cross-sectional & U.S. population & $\begin{array}{l}\text { Greater supply of primary care physicians is associated with lower } \\
\text { incidence of cervical cancer. }\end{array}$ \\
\hline Gorey et al. $(51,52)$ & Longitudinal study & $\begin{array}{l}17,820 \text { Canadian female } \\
\text { breast cancer patients }\end{array}$ & $\begin{array}{l}\text { Primary care physician supplies seem to matter in the effective provi- } \\
\text { sion of cancer care. }\end{array}$ \\
\hline Roetzheim et al. $(53,54)$ & Cross-sectional & U.S. Florida's population & $\begin{array}{l}\text { Incidence and mortality of colorectal cancer decreased in Florida } \\
\text { counties that had an increased supply of primary care physicians. }\end{array}$ \\
\hline
\end{tabular}


Table 2. Intervention studies evaluating the effect of nutrition support (i.e., screening) on clinical outcomes

\begin{tabular}{|l|l|l|l|}
\hline Studies & Design & Sample & Main finding(s) \\
\hline Rypkema et al. (65) & Intervention study & 298 geriatric inpatients & $\begin{array}{l}\text { Intervention resulted in significant increase in weight and decrement in } \\
\text { hospital infections. }\end{array}$ \\
\hline Brugler et al. (64) & Intervention study & 635 inpatients & $\begin{array}{l}\text { Increase in identification of high risk patients. Improved timeliness } \\
\text { of nutritional intervention. Significant decrement in length of stay in } \\
\text { hospital, complications and 30-day readmission rate. }\end{array}$ \\
\hline $\begin{array}{l}\text { Kruizenga et al. (66) } \\
\text { Bl. (62) }\end{array}$ & Intervention study & $\begin{array}{l}588 \text { medical and surgical } \\
\text { inpatients }\end{array}$ & $\begin{array}{l}\text { Increase in recognition of malnourished patients. Significant decre- } \\
\text { ment in length of stay in hospital. }\end{array}$ \\
\hline O'Flynn et al. (67) & Elderly inpatients & $\begin{array}{l}\text { No difference in proportion of unrecognised at-risk patients. Significant } \\
\text { decrement in misclassification rate. } \\
\text { Increment in distribution of oral nutritional supplements. }\end{array}$ \\
\hline Pepersack T. (68) & Intervention study & General inpatients & $\begin{array}{l}\text { Significantly decrement in prevalence of malnutrition. Significant } \\
\text { increase in the proportion of patients weighed on admission. }\end{array}$ \\
\hline
\end{tabular}

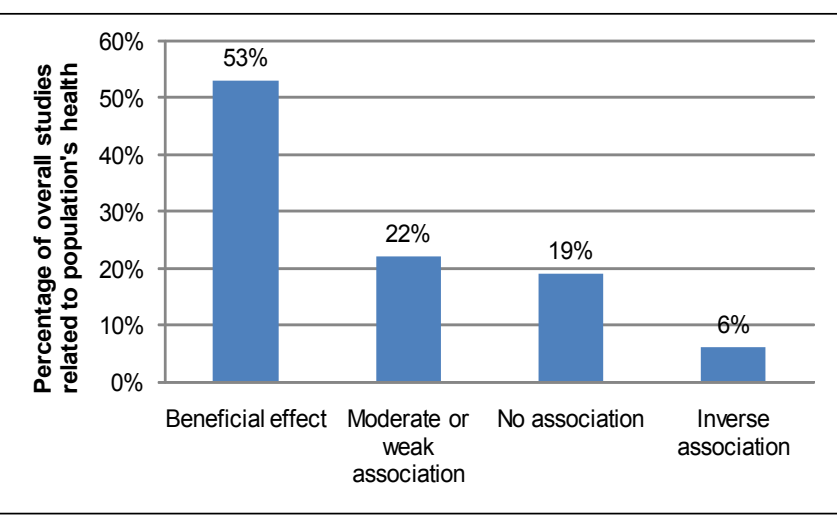

Fig. 1. A summary of studies $(n=32)$ that evaluated the presence of Health Care Services on population's health.

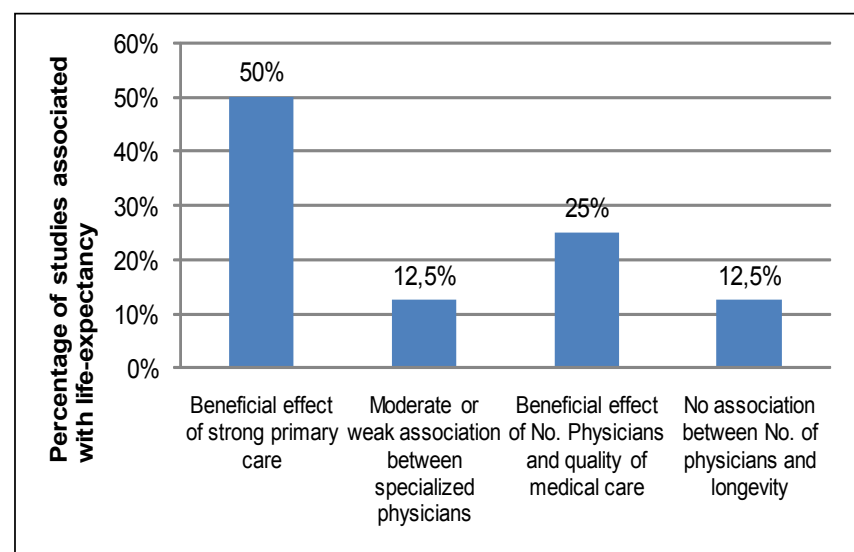

Fig. 2. A summary of studies ( $n=24)$ that evaluated the effect of different types of Health care Services on population's health.

(23-54). This favourable association of medical resources and health has not, always, been accepted. Analysis of long-term mortality trends in the United States from 1900 to 1973 found that medical care could account for very little of the overall decline in mortality (23, 24). McKeown (23), McKinlay et al. (24) have questioned the role of medical care in these gains. From the 1950s to the 1980s, the physician and demographic historian Thomas

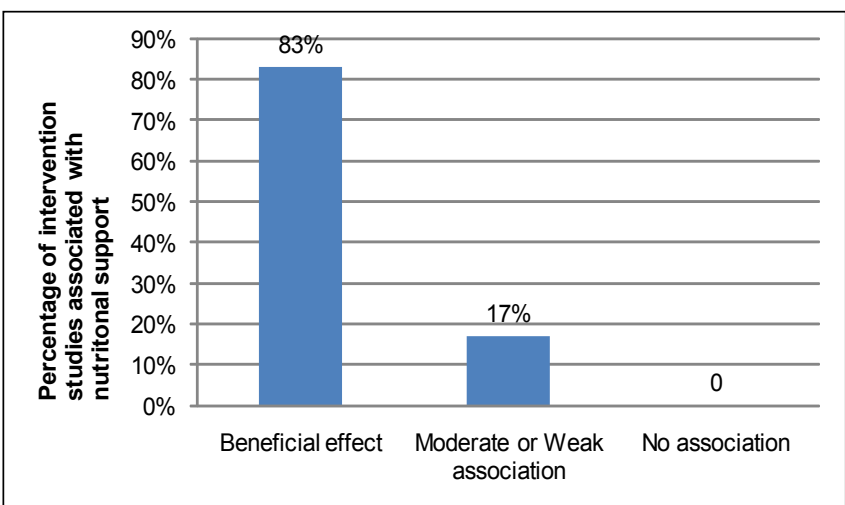

Fig. 3. A summary of studies ( $n=6)$ that evaluated the role of nutritional services (screening) and other strategies on clinical outcomes.

McKeown put forth the view that the growth in population in the industrialized world, from the late 1700 s to the present, was not due to life-saving advancements in the field of medicine or public health. The main factors were the improvements in the overall standards of living, especially diet and nutritional status, resulting from better economic conditions. His historic analysis called into question the effectiveness of some of the most basic and widely applied techniques in the public health care services. Others like Mackenbach $(25,26)$ and Bunker et al. $(27)$ contend that medical care has reasonably contributed to the mortality decline. According to Mackenbach $(25,26)$ reductions in mortality, from conditions which have become amenable to medical intervention, have appreciably contributed to these gains in life expectancy. Without these mortality declines, life expectancy would have decreased by a year in males and increased in females by only 2 years. Furthermore, Bukner and colleagues (27), presented that medical services seem to add, almost, five-years increase in life expectancy since 1900 and almost 7 years of increase since 1950 .

Other studies found that the supply of physicians has been observed to have a "persistent but puzzling positive correlation" with mortality rates that could not be "adjusted away" by covariates such as income. The positive association of physicians' per capita and age-standardised mortality has been repeatedly found since 1978. According to the authors, this correlation was spuri- 
ous and arose from the dynamics of newly industrial regions (28). Inverse relationships (more physicians associated with lower mortality) have been reported, for the United States, as to the overall physician supply (29-37) as well as for the supply of primary care physicians (30). In one of the first studies of this type, Shi and colleagues (31) found that primary care had an independent and positive impact on health indicators and that in multivariate models controlling for demographic, income, and health system covariates, primary care actually reduced the magnitude of the deleterious impact of income inequality on health outcomes. Furthermore, Shi and colleagues presented that the greater number of physicians are associated with a lower mortality from cardiovascular diseases and cancer. In particular, an increase of 1 primary care doctor per 10,000 persons was associated with an increase of 0.67 year of life expectancy $(p<0.001)$ (32). Macinko and colleagues presented the opinion that strong primary care system and practice characteristics, such as geographic regulation, coordination, and community orientation, were associated with improved population health (8). In the regression analysis, primary care was inversely associated with all-cause mortality rates independently, within a model of macro-level health determinants, and also in the full model that includes aggregated individual determinants of health. In all models the primary care score was significant $(\mathrm{p}<0.05)$, although the effect of primary care was partially reduced in the presence of environmental factors, and further reduced by the presence of aggregate individual health determinants. Also, the numbers of physicians and GDP per capita are also negatively associated with all-cause mortality $(p<0.001)$ (8). Furthermore, according to Starfield and colleagues there is already considerable evidence that increasing the supply of primary care physicians would have a beneficial impact on the health of the population $(29,30)$. Especially, the ratio of primary care to population was significantly associated with a lower total heart disease, and cancer mortality, whereas the ratio of specialist to population was generally associated with higher mortality (29).

On the contrary, some researches refer to a "paradox" in primary care. Some studies presented evidence with regards to regionally focused association alone, between the psysician supply and mortality, contrary to former studies, which presented weak or no association (38-41). Particularly, Ricketts and Holmes showed that these relationships are not consistent across the United States. There are regions where stronger and weaker associations persist, between the type of practitioner and all cause mortality, and other regions where no association is apparent (42). Also, some other studies presented that after the regression analysis there was not a significant relationship between general physicians and mortality rates (43) but a significant effect $(p<0.05)$ of the composition of physicians exists where the presence of more independent contract physicians reduces mortality rates compared to situations where more of them are employed by the municipality (44). In UK, Gulliford and colleagues found that one unit increase in the general practitioners supply was associated with a decrease in hospital admissions rates for acute $(-14.4,-21.4$ to -7.4 per $100,000, \mathrm{p}<0.001)$ and chronic conditions $(-10.6,-17.2$ to -4.0 , $\mathrm{p}<0.001)$ (45). Particularly, it seems that in UK, mortality is weakly associated with the degree of organisation of health care practices as represented by the partnership size but not with the supply of general physicians (46). Furthermore, a recent review concludes that the paradox between primary and specialty care exists. When comparing primary to specialty care, it seems that primary care is related with poorer quality care for individual diseases and similar functional health status at lower cost - for people with chronic disease. However primary care seems to provide better quality, health, at a lower cost for people (55). Finally, from the majority of the studies, there seems to be a beneficial contribution of physicians supply (specialist and general) and primary care in population's health, but this association needs further examination.

There is some evidence that countries characterized by a strong primary care orientation, have more equitable health outcomes than those systems oriented toward specialty care (29-31). In Europe, it appears that health reform has not uniformly targeted primary care. Those countries that began to reform their primary care systems in the 1970s and 1980s have made progress in improving both structural features and practice characteristics of these systems. The basic aims of health reform in the European countries at that time were a universal right to health care services for all citizens, a just geographical distribution of resources, and effective cost containment (56). However, other countries with the weakest primary care systems have not generally made much progress in improving either primary care structure or practice (8). Finally, with regards to human resources, over-availability of doctors is noted in South Europe and at the same time an inadequate number of nursing personnel.

In Greece, the health care system was organized in 1983 into the National Health System (named ESY) and incorporated the Beveridge model in the category (57). Except ESY, the private sector and the social insurance both play an important role. Regarding the Greek reality, the available data presented over-availability in doctors and deficits in nursing personnel, with wide discrepancies in their distributions in various regions of the country. In 2000, there were 53,200 doctors in the country or 42 doctors per 10,000 population making Greece second in Europe (after Spain) in the ratio of physicians per population (57). Nevertheless, there is a wide variation between the distribution of doctors in different regions, since, in the greater Athens area in 2000, there were 88 doctors per 10,000 people, whereas in other regions (Central Greece and the Aegean Islands) the corresponding ratio is less than 30. A certain increase in the number of nursing staff has been observed in the country, but this is comparatively low to the increase observed in other European countries. Despite this increase, discrepancies in the distribution of nurses between rural and urban areas still exist (57). A recent survey reported that better management of persistent primary care use, may address the patients' underlying problems, reduce unnecessary demand, and relieve some of the pressure on the capacity of primary care providers to deliver care to all patients (58). The majority of studies underlined the necessity for re-organization of the Greek national health care system and the appearance of a strong primary care (59). However, there are very limited reports that have assessed associations between health care services (supply of physicians and other health care scientists) and health outcomes in Greece.

\section{Nutritional services and health outcomes}

Recent studies reported that there is an association between low access to primary care doctors and higher population mortality $(32,33)$. The majority of these studies focused on mortality rates 
at hospital level, where resource use, policy changes relating to reimbursement rates, doctor and nurse staffing, managed care, and technological change are important explanatory factors for mortality rates (60). Also, another line of research has focused on the effect of the number of physicians or general practitioners in a district (usually US state level or national level) on mortality (35-37). The majority of studies assessing nutritional care services have been researched at a clinical environment. This interest arose due to a number of reports showing a disturbing prevalence of malnutrition in a variety of healthcare settings and patient groups (61). Even in this part, there is limited evidence to support interventions designed to improve nutritional care, in particular with reference to their effects on nutritional and clinical outcomes and costs.

A small number of studies were identified investigating the impact of nutritional screening, together with other interventions on patient outcome, length of stay and costs (62-68). Only one study was identified that observed the effects of screening alone on outcomes (62). This study compared the use of a nutritional screening tool to the usual care. Although screening resulted in an increased recording of patient weight, there was no change in patient care at mealtimes and no difference in dietetic referral. Rypkema et al., (65) showed that, if overall costs are taken into account, screening with appropriate follow-up action produces cost savings as well as clinical benefits (i.e., average weight loss vs. weight gain, $\mathrm{p}<0.001)$. Three recent $(62,63,68)$ studies suggest that assessment and nutritional care planning may be a necessary part of the nutritional care package. This, however, requires a confirmation from larger, more robust studies. Furthermore, it is well known that there is strong association between nutrition and chronic diseases such as obesity, diabetes, hypertension and hypercholesterolemia (19). There are few review reports that include dietary advice interventions given to 'healthy' adults (69, 70). According to the researchers, it seems that brief nutritional educative interventions are modestly effective in reducing blood lipid levels, blood pressure and dietary fat intake, and increasing fruit and vegetable intake $(69,70)$. The burden of these diseases, by that time, has deep impact in younger and middle-aged adults but even more in older ages. Current dietary recommendations underline that the nutritional needs vary by age, but there is limited evidence to support the role of nutritional services in middle aged and older population's health. However it seems, even from this limited number of studies, that nutritional support could be effective as to the clinical outcomes in hospitalized patients as to cardiovascular risk in non-hospitalised individuals.

\section{CONCLUSION}

The majority of the published studies have investigated the role of physicians supply in the population's longevity. It can be concluded that areas with strong primary health care and adequate physician's supplies have better population's health status. Moreover, the nutritional care seems to effectively support the clinical outcome of hospitalised patients, while dietary advice appears to be quite effective on beneficial changes in diet and overall risk. However, the role of dieticians and nutrition practitioners within the health care system, in relation to the population's health, has not been adequately studied. Health and nutritional policy should face health-related problems, calling for an involvement of different stakeholders and an inter-sectoral approach at national, local and community level. Thus, the health care system, have to shift the provided health care services from curative to preventive; and therefore, strong emphasis should be given on health promotion, nutritional education, disease prevention, rehabilitation and public nutritional services.

\section{REFERENCES}

1. Donabedian A. Aspects of medical care administration: specifying requirements for health care. Cambridge MA: Harvard University Press; 1973.

2. National Public Health Performance Standards Program [Internet]. Washington: American Public Health Association; 2011 [cited 2010 March 1]. Available from: http://www.apha.org/programs/standards/ performancestandardsprogram/.

3. Jamrozik K, Hobbs M. Medical care and public health. In: Detels R, McEwen J, Beaglehole R, Tanaka H, editors. Oxford textbook of public health. Oxford: Oxford University Press; 2002. p. 213-42.

4. Gröne O, Garcia-Barbero M. Integrated care: a position paper of the WHO European Office for Integrated Health Care Services. Int J Integr Care. 2001 Apr-Jun;1:e21.

5. Wallace R. Wallace/Maxcy-Rosenau-Last public health \& preventive medicine. New York: McGraw; 2008.

6. Writing Group of the Nutrition Care Process/Standardized Language Committee. Nutrition care process and model part I: the 2008 update. $\mathrm{J}$ Am Diet Assoc. 2008 Jul;108(7):1113-7.

7. Stitzel KF; American Dietetic Association. Position of the American Dietetic Association: the roles of registered dietitians and dietetic technicians, registered in health promotion and disease prevention. J Am Diet Assoc. 2006 Nov;106(11):1875-84.

8. Macinko J, Starfield B, Shi L. The contribution of primary care systems to health outcomes within Organization for Economic Cooperation and Development (OECD) countries, 1970-1998. Health Serv Res. 2003 Jun;38(3):831-65.

9. World Health Organization. The World health report 2002: reducing risks, promoting healthy life. Geneva: World Health Organization; 2002.

10. Mathers CD, Iburg KM, Salomon JA, Tandon A, Chatterji S, Ustün B, et al. Global patterns of healthy life expectancy in the year 2002. BMC Public Health. 2004 Dec 24;4:66.

11. World Health Organization. Active ageing: a policy framework [Internet]. Geneva: World Health Organization [cited $2010 \mathrm{Feb} 18]$. Available from: http://whqlibdoc.who.int/hq/2002/WHO NMH NPH 02.8.pdf.

12. Yusuf S, Hawken S, Ounpuu S, Dans T, Avezum A, Lanas F; INTERHEART Study Investigators. Effect of potentially modifiable risk factors associated with myocardial infarction in 52 countries (the INTERHEART study): case-control study. Lancet. 2004 Sep 11-17;364(9438):937-52.

13. Watt GC, Ecob R. Analysis of falling mortality rates in Edinburgh and Glasgow. J Public Health Med. 2000 Sep;22(3):330-6.

14. Manton KG. Changing concepts of morbidity and mortality in the elderly population. Milbank Mem Fund Q Health Soc. 1982;60(2):183-244.

15. Manton KG, Gu X, Lamb VL. Change in chronic disability from 1982 to $2004 / 2005$ as measured by long-term changes in function and health in the U.S. elderly population. Proc Natl Acad Sci U S A. 2006 Nov 28;103(48):18374-9.

16. Melzer D, McWilliams B, Brayne C, Johnson T, Bond J. Profile of disability in elderly people: estimates from a longitudinal population study. BMJ. 1999 Apr 24;318(7191):1108-11.

17. Menotti A, Kromhout D, Blackburn H, Fidanza F, Buzina R, Nissinen A; The Seven Countries Study Research Group. Food intake patterns and 25-year mortality from coronary heart disease: cross-cultural correlations in the Seven Countries Study. Eur J Epidemiol. 1999 Jul;15(6):507-15.

18. World Health Organization. World health report 2001: mental health: new understanding, new hope. Geneva: World Health Organization; 2001.

19. Keys A, Menotti A, Karvonen MJ, Aravanis C, Blackburn H, Buzina R, et al. The diet and 15-year death rate in the seven countries study. Am J Epidemiol. 1986 Dec;124(6):903-15.

20. Haveman-Nies A, de Groot LC, van Staveren WA. Dietary quality, lifestyle factors and healthy ageing in Europe: the SENECA study. Age Ageing. $2003 \mathrm{Jul} ; 32(4): 427-34$. 
21. Tyrovolas S, Psaltopoulou T, Pounis G, Papairakleous N, Bountziouka $\mathrm{V}$, Zeimbekis A, et al. Nutrient intake in relation to central and overall obesity status among elderly people living in the Mediterranean islands: The MEDIS study. Nutr Metab Cardiovasc Dis. 2010 Feb 11. In press.

22. Idler EL, Benyamini Y. Self-rated health and mortality: a review of twentyseven community studies. J Health Soc Behav. 1997 Mar;38(1):21-37.

23. McKeown T. The role of medicine: dream, mirage, or nemesis? London: Nuffield Provincial Hospital Trust; 1976.

24. McKinlay JB, McKinlay SM. The questionable contribution of medical measures to the decline of mortality in the United States in the twentieth century. Milbank Mem Fund Q Health Soc. 1977;55(3):405-28.

25. Mackenbach JP, Looman CW, Kunst AE, Habbema JD, van der Maas PJ. Post-1950 mortality trends and medical care: gains in life expectancy due to declines in mortality from conditions amenable to medical intervention in The Netherlands. Soc Sci Med. 1988;27(9):889-94.

26. Mackenbach JP. The contribution of medical care to mortality decline: McKeown revisited. J Clin Epidemiol. 1996 Nov;49(11):1207-13.

27. Bunker JP, Frazier HS, Mosteller F. Improving health: measuring effects of medical care. Milbank Q. 1994;72(2):225-58.

28. Young FW. An explanation of the persistent doctor-mortality association J Epidemiol Community Health. 2001 Feb;55(2):80-4.

29. Starfield B, Shi L, Grover A, Macinko J. The effects of specialist supply on populations' health: assessing the evidence. Health Aff (Millwood) 2005 Jan-Jun;Suppl Web Exclusives:W5-97-W5-107.

30. Starfield B, Shi L, Macinko J. Contribution of primary care to health systems and health. Milbank Q. 2005;83(3):457-502.

31. Shi L. Primary care, specialty care, and life chances. Int J Health Serv. 1994;24(3):431-58.

32. Shi L, Macinko J, Starfield B, Wulu J, Regan J, Politzer R. The relationship between primary care, income inequality, and mortality in US states, 1980-1995. J Am Board Fam Pract. 2003 Sep-Oct;16(5):412-22.

33. Shi L, Macinko J, Starfield B, Xu J, Politzer R. Primary care, income inequality, and stroke mortality in the United States: a longitudinal analysis, 1985-1995. Stroke. 2003 Aug;34(8):1958-64.

34. Shi L, Macinko J, Starfield B, Politzer R, Wulu J, Xu J. Primary care, social inequalities and all-cause, heart disease and cancer mortality in US counties: a comparison between urban and non-urban areas. Public Health. 2005 Aug;119(8):699-710.

35. Or Z. Determinants of health outcomes in industrialized countries: a pooled cross-country, time-series analysis. OECD Economic Studies No. 30. Paris: Organisation for Economic Cooperation and Development; 2000 .

36. Or Z, Wang J, Jamison D. International differences in the impact of doc tors on health: a multilevel analysis of OECD countries. J Health Econ. 2005 May;24(3):531-60.

37. Robst J, Graham GG. Access to health care and current health status: do physicians matter? Appl Econ Lett. 1997;4:45-8.

38. McKeown T, Brown RG. Medical evidence related to English population changes in the eighteenth century. Popul Stud. 1955;9:119-41.

39. McKeown T, Record RG. Reasons for the decline of mortality in England and Wales during the nineteenth century. Popul Stud. 1962;16:94-122.

40. Mackenbach JP, Kunst AE, Looman CW, Habbema JD, van der Maas PJ Regional differences in mortality from conditions amenable to medical intervention in The Netherlands: a comparison of four time periods. J Epidemiol Community Health. 1988 Dec;42(4):325-32.

41. Cochrane AL, Leger AS, Moore F. Health service 'input' and mortality 'output' in developed countries. J Epidemiol Community Health. 1978;32:200-5.

42. Ricketts TC, Holmes GM. Mortality and physician supply: does region hold the key to the paradox? Health Serv Res. 2007 Dec;42(6 Pt 1):223351; discussion 2294-323.

43. Poikolainen K, Eskola J. Health services resources and their relation to mortality from causes amenable to health care intervention: a crossnational study. Int J Epidemiol. 1988 Mar;17(1):86-9.

44. Aakvik A, Holmås TH. Access to primary health care and health outcomes: the relationships between GP characteristics and mortality rates. J Health Econ. 2006 Nov;25(6):1139-53

45. Gulliford MC. Availability of primary care doctors and population health in England: is there an association? J Public Health Med. 2002 Dec;24(4):252-4.

46. Gulliford MC, Jack RH, Adams G, Ukoumunne OC. Availability and structure of primary medical care services and population health and health care indicators in England. BMC Health Serv Res. 2004 Jun $11 ; 4(1): 12$.

47. Mansfield CJ, Wilson JL, Kobrinski EJ, Mitchell J. Premature mortality in the United States: the roles of geographic area, socioeconomic status, household type, and availability of medical care. Am J Public Health. 1999 Jun;89(6):893-8.

48. Alter DA, Stukel TA, Newman A. The relationship between physician supply, cardiovascular health service use and cardiac disease burden in Ontario: supply-need mismatch. Can J Cardiol. 2008 Mar;24(3):187-93.

49. Lee J, Park S, Choi K, Kwon SM. The association between the supply of primary care physicians and population health outcomes in Korea. Fam Med. 2010 Oct;42(9):628-35.

50. Campbell RJ, Ramirez AM, Perez K, Roetzheim RG. Cervical cancer rates and the supply of primary care physicians in Florida. Fam Med. 2003 Jan;35(1):60-4

51. Gorey KM, Luginaah IN, Holowaty EJ, Fung KY, Hamm C. Associations of physician supplies with breast cancer stage at diagnosis and survival in Ontario, 1988 to 2006. Cancer. 2009 Aug 1;115(15):3563-70.

52. Gorey KM, Luginaah IN, Fung KY, Bartfay E, Hamm C, Wright FC, et al. Physician supply and breast cancer survival. J Am Board Fam Med. 2010 Jan-Feb;23(1):104-8

53. Roetzheim RG, Gonzalez EC, Ramirez A, Campbell R, van Durme DJ. Primary care physician supply and colorectal cancer. J Fam Pract. 2001 Dec;50(12):1027-31

54. Roetzheim RG, Pal N, Gonzalez EC, Ferrante JM, Van Durme DJ, Ayanian JZ, et al. The effects of physician supply on the early detection of colorectal cancer. J Fam Pract. 1999 Nov;48(11):850-8.

55. Stange KC, Ferrer RL. The paradox of primary care. Ann Fam Med. 2009 Jul-Aug;7(4):293-9.

56. Mossialos E, McKee M. A new European health strategy. BMJ. $2000 \mathrm{Ju}$ $1 ; 321(7252): 6$

57. Tountas Y, Karnaki P, Pavi E. Reforming the reform: the Greek National Health System in transition. Health Policy. 2002 Oct;62(1):15-29.

58. Noula M, Gesouli E, Vobiris G, Raftopoulos V. Projection of the use of primary health care services in a Greek primary health centre: a pilot study. Health Sci J. 2007;1(4).

59. Souliotis K, Lionis C. Creating an integrated health care system in Greece: a primary care perspective. J Med Syst. 2005 Apr;29(2):187-96.

60. Kessler DP, McClellan MB. Is hospital competition socially wasteful? Q J Econ. 2000;115:577-615.

61. Thomas JM, Isenring E, Kellett E. Nutritional status and length of stay in patients admitted to an Acute Assessment Unit. J Hum Nutr Diet. 2007 Aug;20(4):320-8.

62. Bourdel-Marchasson I, Barateau M, Sourgen C, Pinganaud G, SalleMontaudon N, Richard-Harston S, et al. Prospective audits of quality of PEM recognition and nutritional support in critically ill elderly patients. Clin Nutr. 1999 Aug;18(4):233-40.

63. Jordan S, Snow D, Hayes C, Williams A. Introducing a nutrition screening tool: an exploratory study in a district general hospital. J Adv Nurs. 2003 Oct;44(1):12-23

64. Brugler L, DiPrinzio MJ, Bernstein L. The five-year evolution of a malnutrition treatment program in a community hospital. Jt Comm J Qual Improv. 1999 Apr;25(4):191-206.

65. Rypkema G, Adang E, Dicke H, Naber T, de Swart B, Disselhorst L, et al. Cost-effectiveness of an interdisciplinary intervention in geriatric inpatients to prevent malnutrition. J Nutr Health Aging. 2004;8(2):122-7.

66. Kruizenga HM, Van Tulder MW, Seidell JC, Thijs A, Ader HJ, Van Bokhorst-de van der Schueren MA. Effectiveness and cost-effectiveness of early screening and treatment of malnourished patients. Am J Clin Nutr. 2005 Nov;82(5):1082-9.

67. O'Flynn J, Peake H, Hickson M, Foster D, Frost G. The prevalence of malnutrition in hospitals can be reduced: results from three consecutive cross-sectional studies. Clin Nutr. 2005 Dec;24(6):1078-88.

68. Pepersack T. Outcomes of continuous process improvement of nutritiona care program among geriatric units. J Gerontol A Biol Sci Med Sci. 2005 Jun;60(6):787-92

69. Brunner EJ, Rees K, Ward K, Burke M, Thorogood M. Dietary advice for reducing cardiovascular risk. Cochrane Database Syst Rev. 2007 Oct 17;(4):CD002128.

70. Thompson RL, Summerbell CD, Hooper L, Higgins JP, Little PS, Talbot $\mathrm{D}$, et al. Relative efficacy of differential methods of dietary advice: a systematic review. Am J Clin Nutr. 2003 Apr;77(4 Suppl):1052S-1057S.

Received March 5, 2010 Accepted in revised form November 10, 2010 